\title{
DIFFERENCES IN DENTAL CALCULUS INDICES AND SALIVARY CALCIUM AND PHOSPHATE LEVELS IN CHILDREN WITH CHRONIC KIDNEY DISEASE UNDERGOING HEMODIALYSIS AND PERITONEAL DIALYSIS THERAPY
}

\author{
THEA KIRANA, HERIANDI SUTADI*, SARWORINI B BUDIARDJO
}

Department Pediatric Dentistry, Faculty of Dentistry, Universitas Indonesia, Jakarta 10430, Indonesia. Email: sutadi.heriandi@gmail.com Received: 24 October 2017, Revised and Accepted: 11 December 2017

\section{ABSTRACT}

Objective: The objective of this study is to analyze the differences in dental calculus indices and calcium and phosphate levels in children with chronic kidney disease undergoing hemodialysis (HD) and peritoneal dialysis (PD) therapy.

Methods: In this cross-sectional study, 15 children undergoing HD therapy and 15 undergoing PD therapy were subjected to intraoral examination for dental calculus indices. Whole unstimulated saliva samples of all subjects were collected and subjected to calcium and phosphate analysis. Statistical analyses were conducted using the Mann-Whitney and independent t-tests.

Results: The dental calculus indices were significantly lower and salivary calcium level was significantly higher in the PD group than those in the HD group $(\mathrm{p}<0.05)$. The salivary phosphate level was lower in the PD group $(\mathrm{p} \geq 0.05)$ but without significance.

Conclusion: The PD group had lower dental calculus indices and higher salivary calcium level. The higher salivary phosphate levels in the HD group may have contribute to the higher dental calculus indices, probably because phosphate plays an important role in dental calculus formation.

Keywords: Chronic kidney disease, Dental calculus indices, Hemodialysis, Peritoneal dialysis, Salivary calcium, Salivary phosphate.

(C) 2018 The Authors. Published by Innovare Academic Sciences Pvt Ltd. This is an open access article under the CC BY license (http://creativecommons. org/licenses/by/4. 0/) DOI: http://dx.doi.org/10.22159/ajpcr.2018.v11i3.23275

\section{INTRODUCTION}

Chronic kidney disease (CKD) is defined as the progressive and chronic deterioration of the kidney due to an irreversible reduction of the glomerular filtration rate [1-3]. Once the decline in kidney function goes beyond the point of compensation, patients develop end-stage renal disease and it is necessary to start renal replacement therapy to ensure survival [4]. Dialysis and transplantation are provided for children with end-stage renal disease, and dialysis is the preliminary treatment before transplantation $[5,6]$. In current clinical practice, there are two major types of dialysis available: Hemodialysis (HD) and peritoneal dialysis (PD). The principle of dialysis therapy is a clearance of blood toxins by exchange of solute and water through a semipermeable membrane as a dialyzer. HD therapy uses a semipermeable synthetic membrane, whereas PD therapy uses the patient's own peritoneal membrane as the dialyzer [4]. Improvements in pediatric nephrology have resulted in increased survival of children with CKD undergoing these therapies [2].

Both CKD and its treatment may affect mineral metabolism, not only in serum but also saliva, especially, in salivary calcium (Ca) and phosphate (P) levels [1,7]. Ca and P play an important role in the calcification process involved in the formation of dental calculus. Dental calculus in healthy children is rare, but several studies have reported an elevated amount of calculus in children with CKD. In a healthy oral environment, saliva is supersaturated with $\mathrm{Ca}$ and $\mathrm{P}$ without precipitation. When this equilibrium is disturbed, it manifests as increased dental calculus formation [8]. The type of dialysis may also be an important factor in the adequacy of $\mathrm{Ca}$ and $\mathrm{P}$ control in dialysis patients [9]. Alteration of the composition of salivary secretion may be correlated with serum biomarkers in dialysis patients [10]. The present study aimed to analyze dental calculus indices and salivary $\mathrm{Ca}$ and $\mathrm{P}$ levels in a group of children with CKD undergoing HD therapy and another group undergoing PD therapy.

\section{METHODS}

This study was approved by the Ethics Committee of the Faculty of Dentistry Universitas Indonesia and Cipto Mangunkusumo Hospital. This study involved observational analytical research and has a crosssectional design. A total of 30 children with CKD, including 15 receiving HD therapy and 15 receiving PD therapy, were selected and subjected to a detailed intraoral examination. The inclusion criteria for both groups were an age of 6-18 years, dialysis duration of over 6 months, and no change in dialysis medication for at least 1 month. Subjects were included in the study after informed consent was obtained. The exclusion criteria were medical problems except kidney disease (such as a history of radiotherapy and Sjogren syndrome), medications that influence the salivary glands and their secretion, lack of cooperation, and inability to spit.

\section{Clinical examination and indices}

Before clinical examination, a detailed medical history was recorded for all participants. The amount of calculus accumulation was evaluated from calculus surface indices. The presence or absence of supra- and/ or sub-gingival calculus was determined from visual and tactile examination using a mouth mirror and dental explorer. Briefly, a score of 0 represents no calculus formation, whereas a score of 3 represents supragingival calculus covering more than two-thirds of the exposed tooth surface or a continuous heavy band of subgingival calculus around the cervical portion of the tooth or both. Two locations were examined: (1) The lingual aspects of the mandibular incisors adjacent to the orifices of the submandibular glands and (2) the buccal aspects of the right and left first upper molars adjacent to the orifices of parotid glands.

\section{Salivary collection}

Unstimulated whole saliva was collected using the spitting method. For the HD group, saliva was collected after a HD session. Briefly, saliva 
was collected between $8 \mathrm{AM}$ and $12 \mathrm{PM}$. The subjects refrained from eating, tooth brushing, or using mouthwash rinses at least $1 \mathrm{~h}$ before spitting. They were asked to collect saliva in their mouth for $1 \mathrm{~min}$ and spit into a salivary collection tube with a maximum volume of $5 \mathrm{ml}$. The collected saliva was stored in an icebox at $4{ }^{\circ} \mathrm{C}$ and then kept at $-20^{\circ} \mathrm{C}$ until analysis.

Saliva samples were thawed and then centrifuged at $1500 \times g$ (3000 rpm) for $15 \mathrm{~min}$ at $22^{\circ} \mathrm{C}$. Ca and $\mathrm{P}$ concentrations in saliva samples were measured using QuantiChrom ${ }^{\mathrm{TM}}$ Calcium (DICA-500) and Phosphate (DIPI-500) Assay Kits, respectively. The standards, samples, and working reagent were transferred into the wells of a clear bottom 96-well plate. After incubation, the optical density was read using a spectrophotometer at $612 \mathrm{~nm}$ for Ca and $620 \mathrm{~nm}$ for $\mathrm{P}$.

\section{Statistical analyses}

Statistical analyses were performed using SPSS 20.00 (SPSS, Chicago, IL, USA). The Shapiro-Wilk test was used to assess the normality of variables. After descriptive analysis, the bivariate associations between variables were analyzed using Mann-Whitney and independent t-tests for quantitative variables. The statistical level of significance was set at $95 \%(\mathrm{p}<0.05)$.

\section{RESULTS}

Table 1 presents the mean values of dental calculus indices in children with CKD receiving HD therapy $(1.389 \pm 0.265)$ and PD therapy (3.114 \pm 0.497$)$. The indices were significantly higher in the HD group than the PD group $(\mathrm{p}<0.05)$. Table 2 summarizes the mean values of salivary Ca levels in children with CKD undergoing HD therapy $(1.389 \pm 0.265 \mathrm{mg} / \mathrm{dl})$ and PD therapy $(3.114 \pm 0.497 \mathrm{mg} / \mathrm{dl})$. The salivary Ca level was significantly higher in the PD group than that in the HD group $(\mathrm{p}<0.05)$. Table 3 presents the mean value of salivary $P$ levels in children with CKD undergoing HD therapy (7.303 \pm 0.609$)$ and PD therapy (5.711 \pm 0.514$)$. The P level was not significantly higher in the HD group than that in the PD group ( $\mathrm{p} \geq 0.05)$.

\section{DISCUSSION}

Children have a lower rate of dental calculus formation compared to adults. Deposits of calculus are commonly found on the buccal surfaces of the maxillary molars and the lingual surfaces of the mandibular anterior teeth around the major salivary gland. In children with CKD, urea nitrogen levels in the saliva are two-fold higher than those in healthy children [11]. An accelerated rate of calculus formation has been reported in dialysis patients, and this is associated with the alkaline environment resulting from elevated urea levels in the saliva. In the present study, the dental calculus indices in children undergoing HD were significantly higher than those of children in the PD group. Several studies reported that patients undergoing PD therapy have a better quality of life and higher education levels. This could be because patients undergoing HD therapy have to spend approximately $4 \mathrm{~h}$ several times a week in dialysis centers, which often leads to postHD fatigue $[4,12,13]$. Oral health negligence could be explained by the routine dependency on health centers and their main concern about other systemic difficulties. PD differs from HD as PD patients can continue dialysis at home. This finding supports the fact that PD groups pay more attention to oral hygiene to prevent calculus formation [13]. The higher amount of dental calculus in the HD group could also be related to the characteristics of their saliva itself and other manifestations of disturbed $\mathrm{Ca} / \mathrm{P}$ homeostasis [1]. Yavuz et al. stated that the type of dialysis may also be an important factor in the adequacy of $\mathrm{Ca}$ and $\mathrm{P}$ control in dialysis patients [9].

A previous study found that the mean levels of $\mathrm{Ca}$ and $\mathrm{P}$ in the serum remained stable for 6 months after dialysis. The levels of serum $\mathrm{Ca}$ were low in patients with CKD and before initiating dialysis. Therefore, patients need calcium supplementation and therapy with Vitamin $\mathrm{D}$ replacement, calcium-based phosphate binders, and $\mathrm{Ca}$ in the dialysate fluid. Serum Ca levels are expected to increase after dialysis is initiated [14]. In the present study, the salivary Ca levels were
Table 1: Differences in dental calculus indices between children with CKD receiving HD and PD therapy

\begin{tabular}{llll}
\hline Group & N & Mean of dental calculus indices & p \\
\hline HD & 15 & $2.375 \pm 0.108$ & 0.005 \\
PD & 15 & $1.688 \pm 0.197$ & \\
Total & 30 & & \\
\hline
\end{tabular}

${ }^{*} \mathrm{p}<0.05$. HD: Hemodialysis, PD: Peritoneal dialysis, CKD: Chronic kidney disease

Table 2: Differences in salivary Ca level between children with CKD receiving $H D$ and $P D$ therapy

\begin{tabular}{llll}
\hline Group & $\mathbf{N}$ & Mean calcium level (mg/dL) & $\mathbf{p}$ \\
\hline HD & 15 & $1.389 \pm 0.265$ & 0.002 \\
PD & 15 & $3.114 \pm 0.497$ & \\
Amount & 30 & & \\
\hline
\end{tabular}

${ }^{*} \mathrm{p}<0.05$. HD: Hemodialysis, PD: Peritoneal dialysis, CKD: Chronic kidney disease

Table 3: Differences in salivary $P$ level between children with CKD receiving $H D$ and $P D$ therapy

\begin{tabular}{llll}
\hline Group & $\mathbf{N}$ & Mean phosphate level $(\mathbf{m g} / \mathbf{d L})$ & $\mathbf{p}$ \\
\hline HD & 15 & $7.303 \pm 0.609$ & 0.056 \\
PD & 15 & $5.711 \pm 0.514$ & \\
Amount & 30 & & \\
\hline
\end{tabular}

${ }^{*} \mathrm{p}<0.05$. HD: Hemodialysis, PD: Peritoneal dialysis, CKD: Chronic kidney disease

significantly higher in the PD group than those in the HD group. This could be a result of the continuous influx of Ca from the PD dialysate fluid. The optimal dialysate $\mathrm{Ca}$ level for PD patients will maintain a neutral calcium balance [15]. Some studies have found reduced Ca levels in HD patients due to decreased levels of active vitamin D metabolites synthesized in the kidneys. The consequence is increased synthesis and secretion of the parathyroid hormone (secondary hyperparathyroidism), which causes low levels of Ca in the HD group [16]. The higher levels of $\mathrm{Ca}$ in $\mathrm{PD}$ patients may also be related to their higher dietary $\mathrm{Ca}$ intake and supplementation that they are recommended [17].

In the present study, the P level was higher in the HD group than in the PD group, although this difference was not statistically significant. Hyperphosphatemia is a major bone and mineral metabolismrelated concern in dialysis patients, and it increases the risk of vascular calcification [18]. More frequent dialysis has been reported to be more effective in achieving the desired serum levels of $\mathrm{P}$ while nearly eliminating the need for P binders. Some studies suggest that continuous PD may be better in controlling hyperphosphatemia than intermittent HD. Lower P levels in PD group are also associated with less vascular calcification compared to that in the HD group [9]. A previous study confirmed that residual renal function (RRF) is one of the key determinants of $\mathrm{P}$ control in PD patients. In the present study, we found that the PD group had higher RRF, which led to lower P and Ca $\times$ P product levels compared to HD patients [19]. This finding may be explained by the lower salivary P level in PD group than that in the HD group.

Early plaque in heavy calculus formers contains more Ca and 3 times more $\mathrm{P}$ than that in non-calculus formers, suggesting that $\mathrm{P}$ may be more critical than $\mathrm{Ca}$ in plaque mineralization and dental calculus formation [20]. In a previous study, P concentrations in the saliva were found to be higher than those in the serum, corresponding to the active mechanism of P secretion from salivary glands. Savica et al. reported that, in HD patients, serum P levels were the only increased predictor saliva excretion [8]. Consequently, on renal function deterioration, more $\mathrm{P}$ is secreted in the saliva, leading to precipitation with $\mathrm{Ca}$ and dental calculus formation, as was observed in this study. This finding also emphasized the key role of $\mathrm{P}$ in dental calculus formation [8]. A previous 
study also showed that only the P concentration in stimulated whole saliva was associated with dental calculus formation, corroborating the findings of Epstein et al., who found that elevated levels of $\mathrm{P}$ and protein may contribute to dental calculus formation [17]. More P is secreted in saliva because of renal function deterioration, and severe RRF may have resulted in the greater amount of dental calculus formation in the HD group.

\section{CONCLUSION}

In summary, PD patients showed lower amounts of dental calculus formation than HD patients did, probably because of differences in $\mathrm{Ca}$ and $\mathrm{P}$ metabolism and oral health habits between the groups. Salivary $\mathrm{P}$ levels were higher in the HD group, suggesting that $\mathrm{P}$ may be more critical than $\mathrm{Ca}$ for dental calculus formation. Further studies are needed to corroborate these preliminary findings.

\section{ACKNOWLEDGMENTS}

The publication of this manuscript is supported by Universitas Indonesia in 2017.

\section{AUTHOR CONTRIBUTIONS}

The authors thank Universitas Indonesia for the financial support and the management of Cipto Mangunkusumo Hospital for their help with locating the nephrology centers where the children were treated. We also thank the pediatrician Dr. Partini P. Trihono for mentoring us and providing access to medical records. This study was designed and coordinated by Heriandi Sutadi, Sarworini Bagio Budiardjo as the principal investigators, provided conceptual and technical guidance for all aspects of the project. Thea Kirana performed the experiment, analyzed data, and wrote the manuscript

\section{CONFLICT OF INTEREST}

The authors declare that they have no conflict of interest.

\section{REFERENCES}

1. Rejane M, Canabarro T, Loren S, Salazar A, Ferreira-pereira A, Maria R, et al. Role of saliva in the caries experience and calculus formation of young patients undergoing hemodialysis. Clin Oral Invest 2015;19:1973-80.

2. Yahwa NB, Ali B. The dental and oral status of children with chronic renal failure. J Indian Soc Pedod Prev Dent 2007;25:106-8.

3. Seraj B, Ahmadi R, Ramezani N, Mashayekhi A, Ahmadi M. Orodental health status and salivary characteristics in children with chronic renal failure. J Dent (Tehran) 2011;8:146-51.

4. Bayraktar G, Kurtulus I, Kazancioglu R, Bayramgurler I, Cintan S, Bural C, et al. Evaluation of periodontal parameters in patients undergoing peritoneal dialysis or hemodialysis. Oral Dis
2008; 14:185-9.

5. Riaño I, Malaga S, Callis L, Loris C, Martin-Govantes J, Navarro M, et al. Towards guidelines for dialysis in children with end-stage renal disease. Pediatr Nephrol 2000;15:157-62.

6. Müller D, Goldstein SL. Hemodialysis in children with end-stage renal disease. Nat Rev Nephrol 2011;7:650-8.

7. Aboelyazeed H, El-haggar S, Okasha K. Comparative study between the effect of histamine receptor antagonists of Type II (Famotidine) and proton pump inhibitors (Omeprazole) on the efficacy of calcium carbonate as phosphate binder in.haemodialysis patient. Int J Pharm Pharm Sci 2017;9:10-4.

8. Davidovich E, Davidovits M, Peretz B, Shapira J, Aframian DJ. The correlation between dental calculus and disturbed mineral metabolism in paediatric patients with chronic kidney disease. Nephrol Dial Transplant 2009;24:2439-45.

9. Yavuz A, Ersoy FF, Passadakis PS, Tam P, Evaggelos DM, Katopodis KP, et al. Phosphorus control in peritoneal dialysis patients. Kidney Int Suppl 2008;73:S152-8.

10. Rodrigues VP, Franco MM, Marques CP, de Carvalho RC, Leite SA, Pereira AL, et al. Salivary levels of calcium, phosphorus, potassium, albumin and correlation with serum biomarkers in hemodialysis patients. Arch Oral Biol 2016;62:58-63.

11. Davidovich E, Frishberg Y, Aframian DJ, Peretz B. Calculus in a toddler with end-stage renal disease due to prune-belly syndrome. Oral Dis 2006;12:63-6.

12. Sihombing J, Hakim L, Andayani TM, Irijanto F. Quality of life of chronic kidney disease patients with routine hemodialysis in general hospitals in Sleman Yogyakarta. Int J Pharm Pharm Sci 2017;9:213-6.

13. Bayraktar G, Kurtulus I, Kazancioglu R, Bayramgurler I, Cintan S, Bural $\mathrm{C}$, et al. Effect of educational level on oral health in peritoneal and hemodialysis patients. Int J Dent 2009;2009:159767.

14. Melamed ML, Eustace JA, Plantinga L, Jaar BG, Fink NE, Coresh J, et al. Changes in serum calcium, phosphate, and PTH and the risk of death in incident dialysis patients: A longitudinal study. Kidney Int 2006;70:351-7.

15. Wang AY. Calcium balance and negative impact of calcium load in peritoneal dialysis patients. Perit Dial Int 2014;34:345-52.

16. Honarmand M, Farhad-Mollashahi L, Nakhaee A, Sargolzaie F. Oral manifestation and salivary changes in renal patients undergoing hemodialysis. J Clin Exp Dent 2017;9:e207-e210.

17. Martins C, Siqueira WL, Primo LG. Dental calculus formation in children and adolescents undergoing hemodialysis. Pediatr Nephrol 2012;27:1961-6

18. Mahdavi-Mazdeh M, Zamyadi M, Norouzi S, Heidary Rouchi A. Management of calcium and phosphorus metabolism in hemodialysis patients in tehran province, Iran. Iran J Kidney Dis 2007;1:25-8.

19. Rroji M, Seferi S, Cafka M, Petrela E, Likaj E, Barbullushi M, et al. Is residual renal function and better phosphate control in peritoneal dialysis an answer for the lower prevalence of valve calcification compared to hemodialysis patients? Int Urol Nephrol 2014;46:175-82.

20. Tawfig A, Alsaadoon A, Alasmari B, Aleid M, Balbhaith M, Aljabr S. Dental calculus formation among recurrent renal calculi formers. Int $\mathrm{J}$ Dent Oral Heal 2017;3:7-12. 